\title{
Microdilution testing reveals considerable and diverse antimicrobial resistance of Escherichia coli, thermophilic Campylobacter spp. and Salmonella spp. isolated from wild birds present in urban areas
}

\author{
Salome Troxler ${ }^{1}$ (D) Claudia Hess $^{1} \cdot$ Cornelia Konicek $^{1} \cdot$ Zdeněk Knotek $^{2}$ • \\ Pavel Barták ${ }^{3}$ Michael Hess ${ }^{1}$
}

Received: 30 November 2016 /Revised: 27 June 2017 / Accepted: 28 June 2017 /Published online: 15 July 2017

(C) The Author(s) 2017. This article is an open access publication

\begin{abstract}
The antimicrobial resistance (AMR) of E. coli, Salmonella spp. and thermophilic Campylobacter spp. isolated from wild birds in the Austrian-Czech border region, predominantly within the vicinity of Vienna and Brno, was determined. Bacteria were isolated from cloacal swabs taken from 53 avian species belonging to 14 orders, the majority being feral pigeons and various songbirds. Consequently, 1978 E. coli, 24 Salmonella and 99 Campylobacter isolates were tested by microdilution method against a panel of 14 (E. coli and Salmonella spp.) or ten antimicrobial substances (Campylobacter spp.). The AMR varied greatly between Austrian and Czech isolates, between different bird and bacterial species and between the different antimicrobials without consistent trends being recognizable. In 331 from 664 birds, differences in the AMR profile between the two or three $E$. coli isolates from the same bird were observed. Concerning $E$. coli, the least effective antimicrobial was cephalotin ( $90.8 \%$ of isolates resistant); for Campylobacter it was trimethoprim-sulfamethoxazole $(71.4 \%$ of isolates
\end{abstract}

Electronic supplementary material The online version of this article (doi:10.1007/s10344-017-1125-2) contains supplementary material, which is available to authorized users.

Salome Troxler

salome.troxler@vetmeduni.ac.at

1 Clinic for Poultry and Fish Medicine, University of Veterinary Medicine Vienna, Veterinärplatz 1, 1210 Vienna, Austria

2 Avian and Exotic Animal Clinic, University of Veterinary and Pharmaceutical Sciences Brno, Palackého tř. 1946/1, 612

42 Brno, Czech Republic

3 State Veterinary Institute Jihlava, Rantiřovska 93, 586 05 Jihlava, Czech Republic resistant). None of the antimicrobials was effective against all E. coli or Campylobacter isolates. In contrast, more than half of the antimicrobials were effective against all Salmonella isolates, but $71.4 \%$ of the Czech Salmonella isolates and all of the Austrian Salmonella isolates were multi-resistant (resistant to three or more antimicrobial substances); streptomycin being the least effective antimicrobial substance $(90.5 \%$ of isolates resistant). It is concluded that AMR in zoonotic bacteria from wild birds in the investigated densely populated areas is widespread and diverse, arguing for certain care at the wildlifehuman interface, but AMR to clinically important and critical antimicrobials is relatively low.

Keywords Antimicrobial resistance - Austria . Campylobacter spp. · Czech Republic · Escherichia coli . Salmonella spp. · Wild birds

\section{Introduction}

Zoonotic bacteria can be transmitted from animals to humans either via direct or indirect contact, e.g. through contaminated food. If these bacteria are resistant to antimicrobials, the effective treatment of human infections is compromised (EFSA and ECDC 2015). Therefore, antimicrobial resistance (AMR) is a recognized health issue with implications of increased morbidity, mortality and cost rates. However, resistance is complex and dynamic and not yet all contributing factors are known. For example, a reduction in use of a certain antimicrobial substance does not always lead to reduced resistance (Livermore 2003). Also, multi-resistant bacteria were reported in untreated wild populations (Guenther et al. 2011). In case of migrating birds, resistant bacteria can be spread over large distances and even in remote areas, as 
multi-AMR bacteria have been found in arctic wild birds (Sjolund et al. 2008). Furthermore, close contact to potentially AMR bacteria increases the liability of uptake as it was shown that Canada geese in direct contact with liquid waste had more antimicrobial resistances than those without (Cole et al. 2005). Therefore, wild birds are considered an important vector for the distribution of AMR bacteria in the environment and the potential transfer to cattle and other livestock (Cole et al. 2005). Moreover, bacteria isolated from wild birds not only show the AMR situation in wild birds themselves but can also be used as an indicator of the overall environmental AMR situation in a certain region (Hasan et al. 2014).

The ubiquitous presence of Escherichia coli makes them a highly suitable indicator for the situation of AMR in the environment. Furthermore, E. coli could exchange their resistance plasmids with the commensal $E$. coli flora of humans during transient colonization or intestinal passage (EFSA and ECDC $2015)$. Also, some $E$. coli have a zoonotic potential and basically the same extended spectrum $\beta$-lactamases (ESBL)E. coli strains are found in wildlife and in clinical isolates (Guenther et al. 2011). The recent European report on AMR in E. coli from farm animals and food showed moderate to very high levels of resistance to ampicillin, sulfonamides and tetracyclines. The antibiotics with the least resistances were gentamicin, cefotaxime and chloramphenicol. The common core pattern of resistance to ampicillin, streptomycin, sulfonamides, tetracyclines and trimethoprim indicates the presence of class 1 or class 2 integrons (EFSA and ECDC 2015).

Campylobacter spp. and Salmonella spp. are leading causes of bacterial foodborne diseases and fatalities in humans and effective antimicrobial therapy is therefore critical (Scallan et al. 2011; Ge et al. 2013). Wild birds are asymptomatic carriers of these enteropathogens and the bacteria are transmitted to humans directly or indirectly, sometimes resulting in disease outbreaks (Cole et al. 2005; Tizard 2004; Smith et al. 2005; Waldenström et al. 2002). It can be assumed that subclinical human infections are often not recognized but may result in a spread of AMR bacteria.

In Europe, moderate to high AMR rates were reported for tetracyclines, ampicillin and sulfonamides in Salmonella isolates from humans, animals and meat (EFSA and ECDC 2015).

Salmonella isolates from European corvids were most often resistant to nalidixic acid and chloramphenicol; $33 \%$ of the isolates were pansusceptible (Janecko et al. 2015). Eighty percent of Salmonella isolated from wild birds in Spain were pansusceptible, and the three remaining isolates were resistant to aminopenicillins, aminoglycosides, tetracyclines and other antimicrobial substances (Andres et al. 2013).

According to the latest EFSA report, more than half of Campylobacter isolates from humans were resistant to the clinically important antimicrobial ciprofloxacin, but co-resistance to erythromycin was generally low. Also, the majority of Campylobacter isolated from animals and meat was resistant to ciprofloxacin, followed by nalidixic acid and tetracyclines (EFSA and ECDC 2015). Similar resistance rates to ciprofloxacin were found in homing pigeons in Germany (Teske et al. 2013). Even complete resistance against amoxicillin, ciprofloxacin, tetracycline and nalidixic acid was found in Campylobacter isolates from birds of prey in Italy (Dipineto et al. 2014). However, hardly any to relatively low (14.6\% of isolates resistant to metronidazole) AMR rates were observed in various wild birds in Sweden (Waldenström et al. 2005).

The aim of this study was to characterize the AMR situation in selected indicator and zoonotic bacteria isolated from wild birds in the Austrian-Czech border region. To our knowledge, this has not been done before as existing studies from this geographic area are either limited to certain bird or bacteria species (Loncaric et al. 2013; Dolejska et al. 2007, 2009). The data were analysed in regard to differences in the AMR profiles between E. coli, Campylobacter spp. and Salmonella spp. isolated from different bird species, differences between the two countries and differences between the antibiotic substances and number of resistances. Furthermore, in case of $E$. coli, up to three isolates (single colony forming units) per bird were analysed in order to assess the isolates' uniformity in regard to phenotypic AMR.

\section{Material and methods}

\section{Origin of bacteria}

E. coli, Campylobacter and Salmonella isolates were obtained within a prevalence study of zoonotic pathogens in wild birds (Konicek et al. 2016). Birds were sampled within the crossborder region Austria (A)-Czech Republic (CZ). This included mainly the regions Lower Austria (A), Vienna (A), South Bohemia (CZ), South Moravia (CZ) and Vysočina (CZ) (Fig. 1). Cloacal swabs were either obtained from wild birds within routine clinical examinations (A) or the birds were sampled during treatment, survival programs or pest control organized by official authorities (CZ). Altogether, cloacal swabs for bacteriological investigation were collected from 652 birds in Austria and 562 birds in the Czech Republic during the years 2013 and 2014. Following sampling, the swabs were placed in Amies media (eSwab ${ }^{\mathrm{TM}}$, Copan, Brescia, Italy) and stored at $4-8{ }^{\circ} \mathrm{C}$ for a maximum of $48 \mathrm{~h}$ before further processing. Starting volume for each microbial culture was $100 \mu \mathrm{l}$ Amies medium. All isolates were stored a $-80{ }^{\circ} \mathrm{C}$ until AMR test.

\section{Culture of E. coli}

Coliforme agar (Chromocult ${ }^{\circledR}$ Coliforme agar supplemented with $E$. coli/Coliforme selective supplement; Merck KGaA, Darmstadt, Germany) inoculated with $100 \mu \mathrm{l}$ Amies medium 
Fig. 1 Partial map of Austria and Czech Republic showing the location of birds sampled. The size of the dots corresponds to the number of wild birds sampled from these locations (Konicek et al., 2016)

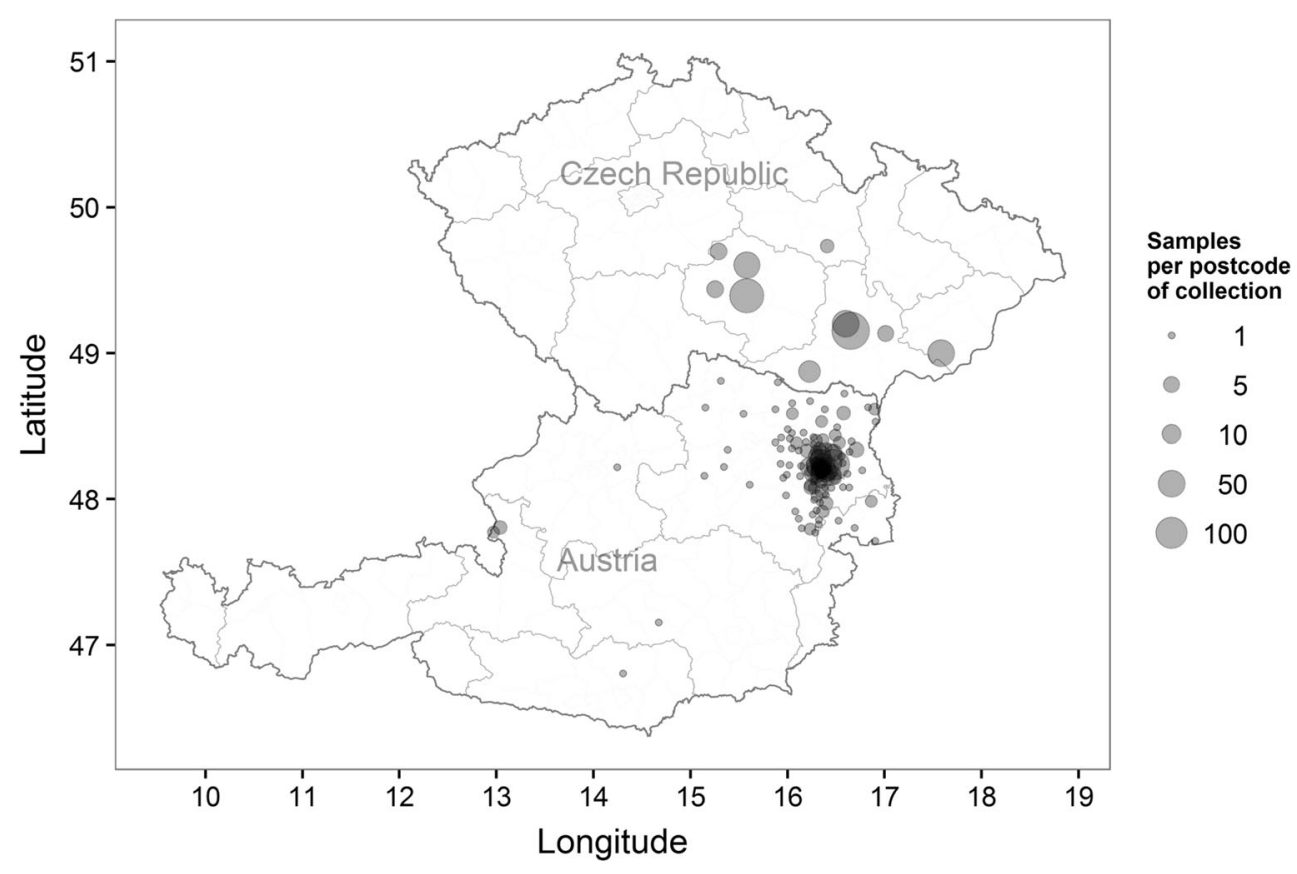

was incubated at $37{ }^{\circ} \mathrm{C}$ for $24 \mathrm{~h}$. In case of characteristic growth, up to three randomly selected single colonies per bird were subcultivated and used for AMR.

\section{Culture of thermophilic Campylobacter spp.}

After selective enrichment in $10 \mathrm{ml}$ of Preston medium (Nutrient Broth No. 2, containing Horse Blood Laked and Preston Campylobacter Selective Supplement; Oxoid, Wesel, Germany) for $41.5^{\circ} \mathrm{C}$ in a microaerobic atmosphere for $24 \mathrm{~h}, 10 \mu \mathrm{l}$ of the Preston fluid were streaked out on Campylobacter Blood-Free Selective Agar Base (CCDA containing CCDA selective supplement; Oxoid Wesel, Germany) and incubated at $41.5^{\circ} \mathrm{C}$ in a microaerobic atmosphere using genbox microaer (bioMérieux Austria GmbH, Vienna, Austria) for $48 \mathrm{~h}$. Confirmation and species identification was done by matrix-associated laser desorption/ionization time of flight mass spectrometry analysis (MALDI-TOF MS) (Alispahic et al. 2010).

\section{Culture of Salmonella spp.}

Isolation of Salmonella spp. was done according to ISO 6579:2002. Briefly, $100 \mu \mathrm{l}$ of the Amies fluid were enriched in buffered peptone water (Lab M, Bury, UK) and then incubated on modified semi-solid rappaport vassiliadis (MSRV) medium containing MSRV selective supplement (Lab M, Bury, UK). Samples with suspicious growth were subcultivated on brilliant green agar (modified) (Lab M, Bury, UK) and xylose lysine decarboxylase agar (Lab M, Bury, UK). From suspicious colonies, Salmonella Oserogroup determination was performed according to the
Kauffmann-White scheme (Popoff and Le Minor 2001) and the isolates were sent to the respective national reference laboratory (Austrian Agency for Health and Food Security, Graz; State Veterinary Institute, Jihlava) for typing.

\section{Antimicrobial resistance (AMR) test}

The broth microdilution method was applied according to CLSI guidelines (Clinical and Laboratory Standards Institute 2014) to test the antimicrobial resistance of the isolated bacteria. E. coli and Salmonella isolates were tested using an individually designed MICRONAUT-S Veterinary plate (MERLIN Diagnostika GmbH, Bornheim-Hersel, Germany). Campylobacter isolates were tested using the commercially available MICRONAUT-S Campylobacter plate (MERLIN Diagnostika GmbH, Bornheim-Hersel, Germany). The antimicrobial substances and their concentrations are given in Online Resource 1. Prior to AMR testing, the bacterial isolates were cultured on Columbia Agar with 5\% sheep blood (bioMérieux Austria GmbH, Vienna, Austria). The E. coli and Salmonella isolates were incubated for $18-24 \mathrm{~h}$ at $37^{\circ} \mathrm{C}$; the Campylobacter isolates in a microaerobic atmosphere for $48 \mathrm{~h}$ at $41.5^{\circ} \mathrm{C}$. The obtained cultures were suspended to McFarland 0.5 in $0.9 \%$ sterile saline solution or, in the case of Campylobacter, MuellerHinton II broth (Becton Dickinson, Heidelberg, Germany). $50 \mu \mathrm{l}$ (E. coli and Salmonella) and $100 \mu \mathrm{l}$ (Campylobacter), respectively, of the suspension were added to $11 \mathrm{ml}$ MuellerHinton II broth and mixed well. The Micronaut test plates were inoculated with $100 \mu \mathrm{l}$ per well and incubated for 18 $24 \mathrm{~h}$ at $37^{\circ} \mathrm{C}$ (E. coli and Salmonella) or for $48 \mathrm{~h}$ at $41.5^{\circ} \mathrm{C}$ in a microaerobic atmosphere (Campylobacter). After 
incubation, the plates were read out by a photometer and analysed by the MCN 6.0 software (MERLIN Diagnostika $\mathrm{GmbH}$, Bornheim-Hersel, Germany). The minimal inhibitory concentrations and susceptibilities were determined according to CLSI guidelines (Clinical and Laboratory Standards Institute 2013, 2014). For further statistical analyses, isolates with the result "intermediate" were classified as "resistant".

\section{Statistics}

To compare antimicrobial resistances between different groups, mean antimicrobial resistance values (the number of antimicrobial substances an isolate is resistant to) were calculated and a two tailed $t$ test was applied. As mentioned before, up to three $E$. coli isolates per bird were tested. If isolates from one bird shared the same AMR profile (being resistant or susceptible to a certain antimicrobial substance), only one was taken for the detailed analyses in order to analyse only unique AMR profiles.

\section{Results}

Within this study 1978 E. coli isolates, 99 Campylobacter isolates and 24 Salmonella isolates from Austrian and Czech wild birds were tested for antimicrobial resistance. The largest number of samples came from birds belonging to the order Columbiformes (47.0\%), Passeriformes (21.4\%), Anseriformes (9.9\%) and raptors (12.6\%; including Accipitriformes, Strigiformes and Falconiformes). Altogether, bacteria from 53 bird species of 14 orders were included in the study (Table 1). 1239 isolates were collected in the Czech Republic (59.0\%) and 862 isolates in Austria (41.0\%). Campylobacter isolates consisted of 88 C. jejuni, nine $C$. coli and two $C$. lari. The Salmonella isolates were further typed as $S$. Infantis $(15 \times), S$. Indiana $(3 \times), S$. Enteritidis $(2 \times), S$. Thompson, $S$. Typhimurium, $S$. Salamae and $S$. Abony (each serotype one isolate).

\section{AMR of $E$. coli}

Up to three $E$. coli isolates (single colony forming units) were tested from each bird in order to identify isolates with different phenotypic AMR profiles. In some cases, only one or two isolates per bird could be obtained ( 71 birds - one isolate, 85 birds - two isolates, 579 birds - three isolates). The resulting numbers are given in Table 2. If two or three isolates from one bird shared the same AMR profile only one profile was included in further analyses. Therefore, the original number of $1978 \mathrm{E}$. coli isolates was reduced to $1149 \mathrm{E}$. coli isolates or unique AMR profiles, coming from 735 birds (Table 1).

By far the most resistances among $E$. coli isolates (Fig. 2a) were observed to the first-generation cephalosporin, cephalotin $(88.25 \%)$. About $40 \%$ of the $E$. coli isolates were resistant to the majority of antimicrobial substances: ampicillin $(44.65 \%)$, ticarcillin $(43.26 \%)$, nalidixic acid $(42.47 \%)$, ticarcillin-clavulanate $(40.64 \%)$, amoxicillin-clavulanate $(37.42 \%)$ and cefoxitin $(36.03 \%)$. More than one quarter of the $E$. coli isolates were resistant to ceftriaxone $(30.72 \%)$, followed by streptomycin $(25.50 \%)$, chloramphenicol $(25.07 \%)$ and trimethoprim-sulfamethoxazole $(22.63 \%)$. $17.93 \%$ of the $E$. coli isolates were resistant to tetracycline and $12.45 \%$ to ciprofloxacin. The least resistances were observed to gentamicin (6.01\%). A classification of isolates as "probably ESBL" was proposed for 342 out of 1149 isolates (335 Czech isolates and 7 Austrian isolates) by the MCN software.

Calculating the mean number of antimicrobial substances, the $E$. coli isolates were resistant to the highest values were noticed for Ciconiiformes (8.89, $n=37$ ), followed by Apodiformes (8.0, $n=3)$, Piciformes (6.63, $n=8)$, Anseriformes $(6.5, n=112)$, Strigiformes $(5.85, n=26)$, Galliformes (5.22, $n=55)$, Accipitriformes (4.68, $n=62$ ), Columbiformes (4.48, $n=557)$, Falconiformes (4.37, $n=62)$, Passeriformes $(3.63, n=219)$ and Gruiformes (3.0, $n=3$ ). E. coli strains isolated from Corvidae (Corvus corone, Corvus monedula and Corvus frugilegus) had a mean AMR value of $3.45(n=133)$. Single or no antimicrobial resistances were found in $E$. coli strains isolated from Alcediniformes (1.00, $n=1)$, Charadriiformes $(0.67, n=3)$ and Cuculiformes $(0.00, n=1)$. For some orders, significant differences between the Austrian and Czech $E$. coli isolates were observed, as shown in Fig. 3 a.

Analysing all E. coli isolates independent of their origin, $8.44 \%$ of them were completely susceptible to all antimicrobial substances tested. Almost one third of the isolates $(32.20 \%)$ were resistant to one antimicrobial substance. Multi-resistant E. coli isolates were more often found in the Czech Republic than in Austria; 60.16\% of the Czech compared to $28.71 \%$ of the Austrian E. coli isolates where resistant to three or more antimicrobial substances. More detailed information is given in Online Resource 2.

\section{AMR of Campylobacter spp.}

Only $29.29 \%$ of the Campylobacter isolates were susceptible to trimethoprim-sulfamethoxazole leading to the highest number of resistant isolates to this antimicrobial substance in both countries (Fig. 2b). Approximately one quarter of the Campylobacter isolates were resistant to the following antimicrobial substances: nalidixic acid (28.28\%), tetracycline (25.25\%), azithromycin, clindamycin (both $23.23 \%$ ), streptomycin $(22.22 \%)$ and ciprofloxacin $(21.21 \%)$. Nearly the same values were obtained for erythromycin $(14.14 \%$ resistant isolates) and chloramphenicol (13.13\% resistant isolates). 
Table 1 Number of bacterial isolates tested for AMR, according to the order and species of the host and geographic region (Austria and Czech Republic). For E. coli, up to three single isolates per bird were tested, and, if unique phenotypic AMR profiles were obtained, each isolate was included in analyses. The number of underlying host birds is given in brackets

\begin{tabular}{|c|c|c|c|c|c|c|c|}
\hline \multicolumn{2}{|l|}{ Avian host } & \multicolumn{3}{|l|}{ Austria } & \multicolumn{3}{|c|}{ Czech Republic } \\
\hline Order & Species & $\begin{array}{l}\text { E. coli } \\
\text { (birds) }\end{array}$ & $\begin{array}{l}\text { Campylobacter } \\
\text { spp. }\end{array}$ & $\begin{array}{l}\text { Salmonella } \\
\text { spp. }\end{array}$ & $\begin{array}{l}\text { E. coli } \\
\text { (birds) }\end{array}$ & $\begin{array}{l}\text { Campylobacter } \\
\text { spp. }\end{array}$ & $\begin{array}{l}\text { Salmonella } \\
\text { spp. }\end{array}$ \\
\hline \multirow{11}{*}{$\begin{array}{l}\text { Birds of prey } \\
\text { (Accipitriformes) }\end{array}$} & & $25(15)$ & & & $37(21)$ & & \\
\hline & Black kite (Milvus migrans) & & & & $1(1)$ & & \\
\hline & Common buzzard (Buteo buteo) & $11(7)$ & & & $12(6)$ & & \\
\hline & $\begin{array}{l}\text { European honey buzzard (Pernis } \\
\text { apivorus) }\end{array}$ & $2(1)$ & & & & & \\
\hline & $\begin{array}{l}\text { Eurasian sparrowhawk (Accipiter } \\
\text { nisus) }\end{array}$ & $6(4)$ & & & $2(2)$ & & \\
\hline & Goshawk (Accipiter gentilis) & & & & $7(4)$ & & \\
\hline & Harris hawk (Parabuteo unicinctus) & $3(1)$ & & & & & \\
\hline & Pallied harrier (Circus macrourus) & $1(1)$ & & & & & \\
\hline & $\begin{array}{l}\text { Rough-legged buzzard (Buteo } \\
\text { lagopus) }\end{array}$ & & & & $3(2)$ & & \\
\hline & $\begin{array}{l}\text { Western marsh harrier (Circus } \\
\text { aeruginosus) }\end{array}$ & & & & $12(6)$ & & \\
\hline & $\begin{array}{l}\text { White-tailed eagle (Haliaeetus } \\
\text { albicilla) }\end{array}$ & $2(1)$ & & & & & \\
\hline \multirow[t]{6}{*}{ Owls (Strigiformes) } & & $19(13)$ & 2 & & $7(4)$ & & \\
\hline & Eurasian eagle owl (Bubo bubo) & & & & & & \\
\hline & Little owl (Athene noctua) & $2(1)$ & & & & & \\
\hline & Long-eared owl (Asio otus) & $8(6)$ & 1 & & $4(2)$ & & \\
\hline & Tawny owl (Strix aluco) & $8(5)$ & 1 & & $3(2)$ & & \\
\hline & Western barn owl (Tyto alba) & $1(1)$ & & & & & \\
\hline \multirow{3}{*}{$\begin{array}{l}\text { Falcons } \\
\qquad \text { (Falconiformes) }\end{array}$} & & $38(25)$ & 2 & 1 & $24(12)$ & & 3 \\
\hline & $\begin{array}{l}\text { Common kestrel (Falco } \\
\text { tinnunculus) }\end{array}$ & $37(24)$ & 2 & 1 & $24(12)$ & & 3 \\
\hline & Eurasian hobby (Falco subbuteo) & $1(1)$ & & & & & \\
\hline \multirow[t]{3}{*}{ Cranes (Gruiformes) } & & $3(2)$ & 1 & & & & \\
\hline & $\begin{array}{l}\text { Common moorhen (Gallinula } \\
\text { chloropus) }\end{array}$ & $1(1)$ & 1 & & & & \\
\hline & Great bustard (Otis tarda) & $2(1)$ & & & & & \\
\hline \multirow{2}{*}{$\begin{array}{l}\text { Cuckoos } \\
\quad \text { (Cuculiformes) }\end{array}$} & & $1(1)$ & 1 & & & & \\
\hline & Common cuckoo (Cuculus canorus) & $1(1)$ & 1 & & & & \\
\hline \multirow[t]{4}{*}{ Fowls (Galliformes) } & & $4(2)$ & & & $51(33)$ & & 15 \\
\hline & $\begin{array}{l}\text { Common pheasant (Phasianus } \\
\text { colchicus) }\end{array}$ & $4(2)$ & & & $41(28)$ & & 14 \\
\hline & $\begin{array}{l}\text { Reeves's pheasant (Syrmaticus } \\
\text { reevesii) }\end{array}$ & & & & $6(3)$ & & \\
\hline & Wild turkey (Meleagris gallopavo) & & & & $4(2)$ & 1 & 1 \\
\hline \multirow{3}{*}{$\begin{array}{l}\text { Gulls, button-quails, } \\
\text { plovers } \\
\text { (Charadriiformes) }\end{array}$} & & $3(2)$ & 2 & 1 & & & \\
\hline & $\begin{array}{l}\text { Black-headed gull (Chroicocephalus } \\
\text { ridibundus) }\end{array}$ & $1(1)$ & 1 & 1 & & & \\
\hline & $\begin{array}{l}\text { Common snipe (Gallinago } \\
\text { gallinago) }\end{array}$ & $2(1)$ & 1 & & & & \\
\hline \multirow{3}{*}{$\begin{array}{l}\text { Kingfishers } \\
\quad \text { (Alcediniformes) }\end{array}$} & & $1(1)$ & & & & & \\
\hline & Common kingfisher (Alcedo atthis) & $1(1)$ & & & & & \\
\hline & & $1(1)$ & & & $2(1)$ & & \\
\hline
\end{tabular}


Table 1 (continued)

\begin{tabular}{|c|c|c|c|c|c|c|c|}
\hline \multicolumn{2}{|l|}{ Avian host } & \multicolumn{3}{|l|}{ Austria } & \multicolumn{3}{|c|}{ Czech Republic } \\
\hline Order & Species & $\begin{array}{l}\text { E. coli } \\
\text { (birds) }\end{array}$ & $\begin{array}{l}\text { Campylobacter } \\
\text { spp. }\end{array}$ & $\begin{array}{l}\text { Salmonella } \\
\text { spp. }\end{array}$ & $\begin{array}{l}\text { E. coli } \\
\text { (birds) }\end{array}$ & $\begin{array}{l}\text { Campylobacter } \\
\text { spp. }\end{array}$ & $\begin{array}{l}\text { Salmonella } \\
\text { spp. }\end{array}$ \\
\hline \multicolumn{8}{|l|}{$\begin{array}{l}\text { Swifts } \\
\quad \text { (Apodiformes) }\end{array}$} \\
\hline & Common swift (Apus apus) & $1(1)$ & & & $2(1)$ & & \\
\hline \multirow[t]{4}{*}{$\begin{array}{l}\text { Pigeons } \\
\text { (Columbiformes) }\end{array}$} & & $116(88)$ & 2 & 1 & $\begin{array}{l}441 \\
\quad(282)\end{array}$ & 34 & \\
\hline & $\begin{array}{l}\text { Collared dove (Streptopelia } \\
\text { decaocto) }\end{array}$ & $7(6)$ & & & & & \\
\hline & $\begin{array}{l}\text { Common wood pigeon (Columba } \\
\text { palumbus) }\end{array}$ & $2(2)$ & & & $2(2)$ & & \\
\hline & $\begin{array}{l}\text { Feral pigeons (Columba livia } \mathrm{f} \text {. } \\
\text { domestica) }\end{array}$ & $107(80)$ & 2 & 1 & $\begin{array}{l}439 \\
(280)\end{array}$ & 34 & \\
\hline \multirow[t]{18}{*}{$\begin{array}{l}\text { Songbirds } \\
\text { (Passeriformes) }\end{array}$} & & $\begin{array}{l}164 \\
(106)\end{array}$ & 35 & & $55(36)$ & 15 & 1 \\
\hline & Carrion crow (Corvus corone) & $104(64)$ & 25 & & $12(9)$ & 2 & \\
\hline & Common Blackbird (Turdus merula) & $24(17)$ & 3 & & $10(5)$ & & \\
\hline & $\begin{array}{l}\text { Common chaffinch (Fringilla } \\
\text { coelebs) }\end{array}$ & $3(1)$ & & & $1(1)$ & & \\
\hline & $\begin{array}{l}\text { Common house martin (Delichon } \\
\text { urbicum) }\end{array}$ & $3(2)$ & & & & & \\
\hline & $\begin{array}{l}\text { Common redstart (Phoenicurus } \\
\text { phoenicurus) }\end{array}$ & $1(1)$ & & & & & \\
\hline & Common starling (Sturnus vulgaris) & $1(1)$ & & & & & \\
\hline & $\begin{array}{l}\text { Eurasian blue tit (Cyanistes } \\
\text { caerulus) }\end{array}$ & $2(1)$ & 1 & & & & \\
\hline & Eurasian jay (Garrulus glandarius) & & & & $1(1)$ & & \\
\hline & Eurasian magpie (Pica pica) & & & & $21(11)$ & 13 & 1 \\
\hline & $\begin{array}{l}\text { European robin (Erithacus } \\
\text { rubecula) }\end{array}$ & $2(1)$ & & & & & \\
\hline & Fieldfare (Turdus pilaris) & & & & $1(1)$ & & \\
\hline & Great tit (Parus major) & $3(3)$ & & & & & \\
\hline & House sparrow (Passer domesticus) & $8(7)$ & & & $1(1)$ & & \\
\hline & Jackdaw (Corvus monedula) & $4(4)$ & 4 & & & & \\
\hline & Rook (Corvus frugilegus) & $6(2)$ & 1 & & $7(6)$ & & \\
\hline & Song thrush (Turdus philomelos) & $1(1)$ & 1 & & $1(1)$ & & \\
\hline & Warbler (Sylvia spp.) & $2(1)$ & & & & & \\
\hline \multirow[t]{2}{*}{$\begin{array}{l}\text { Storks } \\
\text { (Ciconiiformes) }\end{array}$} & & & & & $37(17)$ & & \\
\hline & Grey heron (Ardea cinerea) & & & & $37(17)$ & & \\
\hline \multirow{4}{*}{$\begin{array}{l}\text { Waterfowls } \\
\text { (Anseriformes) }\end{array}$} & & $31(21)$ & 1 & & $81(48)$ & 2 & 2 \\
\hline & Greylag goose (Anser anser) & $1(1)$ & & & $16(9)$ & 1 & 1 \\
\hline & Mallard duck (Anas platyrhynchos) & $24(16)$ & 1 & & $53(31)$ & 1 & 1 \\
\hline & Mute swan (Cygnus olor) & $6(4)$ & & & $12(8)$ & & \\
\hline \multirow{3}{*}{$\begin{array}{l}\text { Woodpeckers } \\
\text { (Piciformes) }\end{array}$} & & $5(3)$ & 1 & & $3(1)$ & & \\
\hline & $\begin{array}{l}\text { Black woodpecker (Dryocopus } \\
\text { martius) }\end{array}$ & $1(1)$ & & & & & \\
\hline & $\begin{array}{l}\text { Great spotted woodpecker } \\
\text { (Dendrocopos major) }\end{array}$ & $4(2)$ & 1 & & $3(1)$ & & \\
\hline Total numbers & & $\begin{array}{l}411 \\
(280)\end{array}$ & 47 & 3 & $\begin{array}{l}738 \\
(455)\end{array}$ & 52 & 21 \\
\hline $\begin{array}{l}\text { Total numbers AT + } \\
\quad \mathrm{CZ}\end{array}$ & & & & & $\begin{array}{l}1149 \\
(735)\end{array}$ & 99 & 24 \\
\hline
\end{tabular}


Table 2 Number of tested single E. coli isolates (colony-forming units), resulting number of unique phenotypic AMR profiles and variation between the AMR profiles of a bird in relation to the number of birds

No. of $E$. coli isolates/no. of birds

\begin{tabular}{|c|c|c|c|c|c|}
\hline & $3 / 579$ & & $2 / 85$ & & $1 / 71$ \\
\hline \multicolumn{6}{|c|}{ No. of AMR profiles/no. of birds } \\
\hline $1 \mathrm{a} / 283$ & $2 / 242$ & $3 / 54$ & $1^{\mathrm{a}} / 50$ & $2 / 35$ & n.a. \\
\hline \multicolumn{6}{|c|}{ Variation between AMR profiles $\mathrm{b} /$ no. of birds } \\
\hline \multirow{12}{*}{ n.a. } & $1 / 182$ & n.a. & n.a. & $1 / 25$ & n.a. \\
\hline & $2 / 18$ & $2 / 18$ & & $2 / 5$ & \\
\hline & $3 / 6$ & $3 / 13$ & & $3 / 0$ & \\
\hline & $4 / 4$ & $4 / 2$ & & $4 / 1$ & \\
\hline & $5 / 8$ & $5 / 4$ & & $5 / 1$ & \\
\hline & $6 / 7$ & $6 / 3$ & & $6 / 1$ & \\
\hline & $7 / 8$ & $7 / 1$ & & $7 / 0$ & \\
\hline & $8 / 5$ & $8 / 6$ & & $8 / 1$ & \\
\hline & $9 / 2$ & $9 / 4$ & & $9 / 1$ & \\
\hline & $10 / 2$ & $10 / 2$ & & $10 / 0$ & \\
\hline & $11 / 0$ & $11 / 0$ & & $11 / 0$ & \\
\hline & $12 / 0$ & $12 / 1$ & & $12 / 0$ & \\
\hline
\end{tabular}

n.a. not applicable

${ }^{\text {a }}$ All isolates from one bird had the same AMR profile

${ }^{\mathrm{b}}$ Variation between the isolates from one bird in the number of antimicrobial substances the isolates were resistant to

Finally, 5.05\% of the Campylobacter isolates were resistant to telithromycin.

Comparing different orders of Campylobacter host birds, Falconiformes had the highest mean AMR value per isolate $(9.50, n=2)$ which resulted in significant differences to the mean AMR values calculated for Columbiformes (2.58, $n=36, p \leq 0.05)$, Passeriformes $(2.26, n=50, p \leq 0.01)$ and Anseriformes (1.33, $n=3, p \leq 0.05)$ (Fig. 3b). A large intragroup variation was observed among Campylobacter isolated from Charadriiformes (AMR value 6.00, $n=2$ ) and Strigiformes (AMR value $5.00, n=2$ ). The single Campylobacter isolates from Gruiformes, Cuculiformes and Piciformes were each resistant to one antimicrobial substance (trimethoprim-sulfamethoxazole) or to three antimicrobial substances (ciprofloxacin, nalidixic acid and streptomycin), in the case of Galliformes.

There were no significant differences in the mean number of antimicrobials the Campylobacter species C. coli and $C$. jejuni were resistant to (3.11 and 2.26, respectively). But there were significant differences $(p \leq 0.05$ and $p \leq 0.01$, respectively) to $C$. lari, as the two $C$. lari isolates were both pansusceptible.

In total, $40.43 \%$ of the Austrian and $30.77 \%$ of the Czech Campylobacter isolates were resistant to three or more antimicrobial substances. The majority (44.68\%) of the Austrian isolates were resistant to one antimicrobial substance, whereas the majority (38.46\%) of Czech isolates were completely susceptible (Online Resource 2).

\section{AMR of Salmonella spp.}

The most resistances among Salmonella isolates was noticed to streptomycin $(83.33 \%)$, followed by tetracycline and nalidixic acid (both $62.50 \%$ ). Exactly half of the Salmonella isolates were resistant to cefoxitin; $41.67 \%$ were resistant to cephalotin and $25.00 \%$ to gentamycin. The Salmonella isolates were completely susceptible to all other antimicrobial substances tested (Fig. 2c).

The three Austrian Salmonella isolates ( $S$. Abony, $S$. Thompson and $S$. Typhimurium) were all resistant to cephalothin, gentamicin and streptomycin but otherwise completely susceptible. $19.05 \%$ of the Czech Salmonella isolates (2 S. Enteritidis and $2 S$. Indiana) were pansusceptible, 9.52\% (1 $S$. Enteritidis and $1 S$. Salamae) were resistant to streptomycin only and the remaining $71.43 \%$ were resistant to three to six antimicrobial substances (Online Resource 2).

Most resistances were counted in Salmonella isolates from Galliformes. Their mean AMR value (4.20) differed significantly $(p \leq 0.01)$ to isolates from Falconiformes and Passeriformes (mean AMR values 1.25 and 0.00 , respectively). No significant difference in the mean AMR values were observed between Salmonella isolates from Galliformes and Anseriformes (mean AMR value 2.00), as well as between Salmonella isolates from Anseriformes and Passeriformes (AMR value 0.00) (Fig. 3c). Within the different Salmonella serotypes, most resistances were found in $S$. Infantis (mean AMR value 4.47), which results in significant differences $(p \leq 0.01)$ to $S$. Enteritidis (mean AMR value 0.00 ), $S$. Indiana (mean AMR value 0.33 ) and $S$. Salamae (AMR value 1.00).

\section{Discussion}

Worldwide, studies about antimicrobial resistances in wild birds have been performed (Bonnedahl and Järhult 2014) but these are mostly limited to certain species or areas. A recent extensive study investigated $E$. coli isolates from gulls from nine European countries and has shown a north-to-south gradient in resistances (Stedt et al. 2014). However, that study did not include samples from central-eastern European countries or other bird species than gulls. The AMR situation in wild birds in the densely populated but also intensively used agricultural region between Austria and Czech Republic has not been investigated so far in detail. Available studies were limited to ESBL producing E. coli and Enterococci or methicillin-resistant Staphylococcus aureus (MRSA) within certain bird species (Loncaric et al. 2013; Dolejska et al. 2007, 2009). 
Fig. 2 Percentage of E. coli (a), Campylobacter spp. (b) and

Salmonella spp. (c) isolates which were resistant to the different antimicrobial substances. The results are shown separately for Austrian (black bars) and Czech isolates (grey bars). The numbers $(n)$ of isolates responding to $100 \%$ are E. coli-Austria $(n=411)$ and Czech Republic ( $n=738)$; Campylobacter spp.Austria $(n=47)$ and Czech Republic ( $n=52)$; Salmonella spp.-Austria $(n=3)$ and Czech Republic $(n=21)$. AMC amoxicillin-clavulanate, $A M P$ ampicillin, $A Z M$ azithromycin, $C I P$ ciprofloxacin, $C L I$ clindamycin, $C M P$ chloramphenicol, $C O X$ cefoxitin, $C R O$ ceftriaxone, $C T N$ cephalothin, $E R Y$ erythromycin, GEN gentamicin, $N A L$ nalidixic acid, STR streptomycin, TEL telithromycin, $T / S$ trimethoprimsulfamethoxazole, TET tetracycline, TIC ticarcillin, TIL ticarcillin-clavulanate a

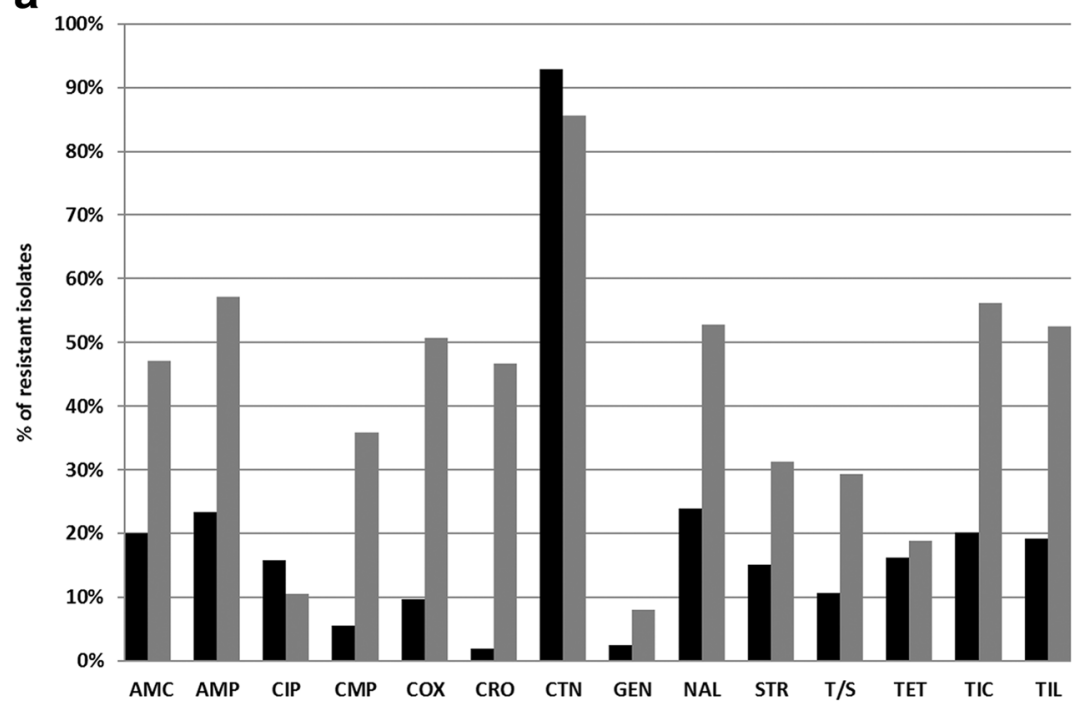

b

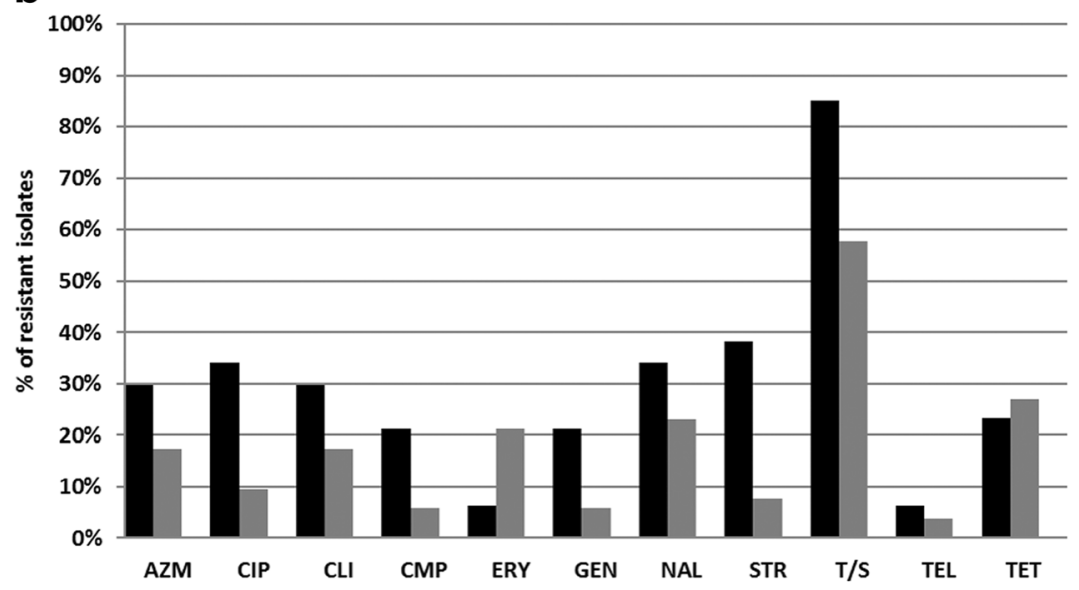

C

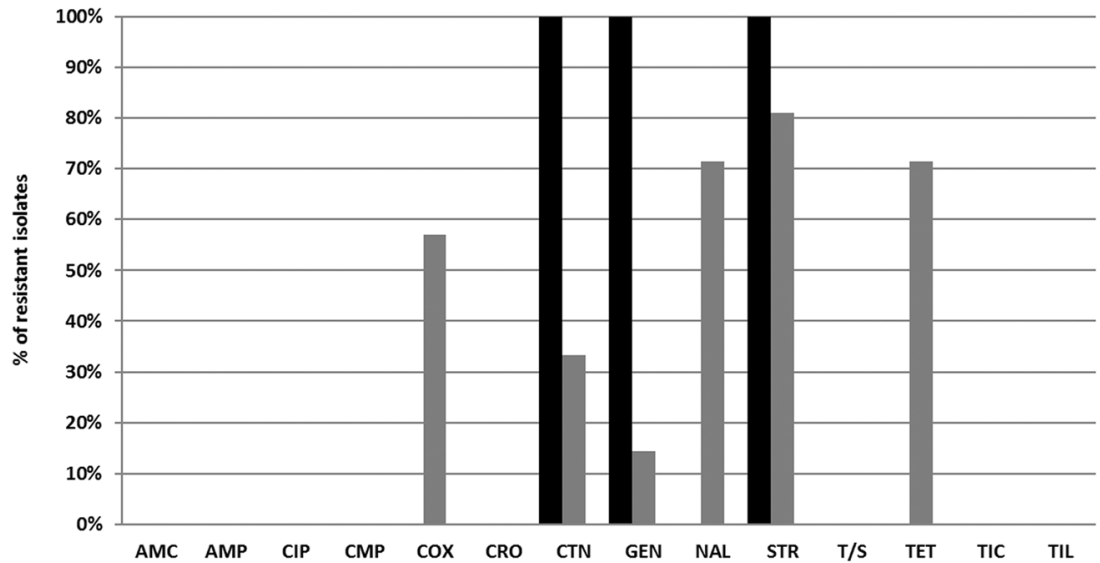

Therefore, it was the aim of the actual study to determine the AMR patterns of E. coli, Salmonella spp. and thermophilic Campylobacter spp. in wild birds living mostly in close contact to humans within the Austrian-Czech border region; a region harbouring important bird areas (BirdLife International 2015a, b). Furthermore, to our knowledge, this is the first study investigating different $E$. coli isolates from the same bird. As expected, the majority of $E$. coli isolates from the same bird shared the same AMR profile or had only minor variations. Still the number of isolates which differed considerably in their susceptibility 

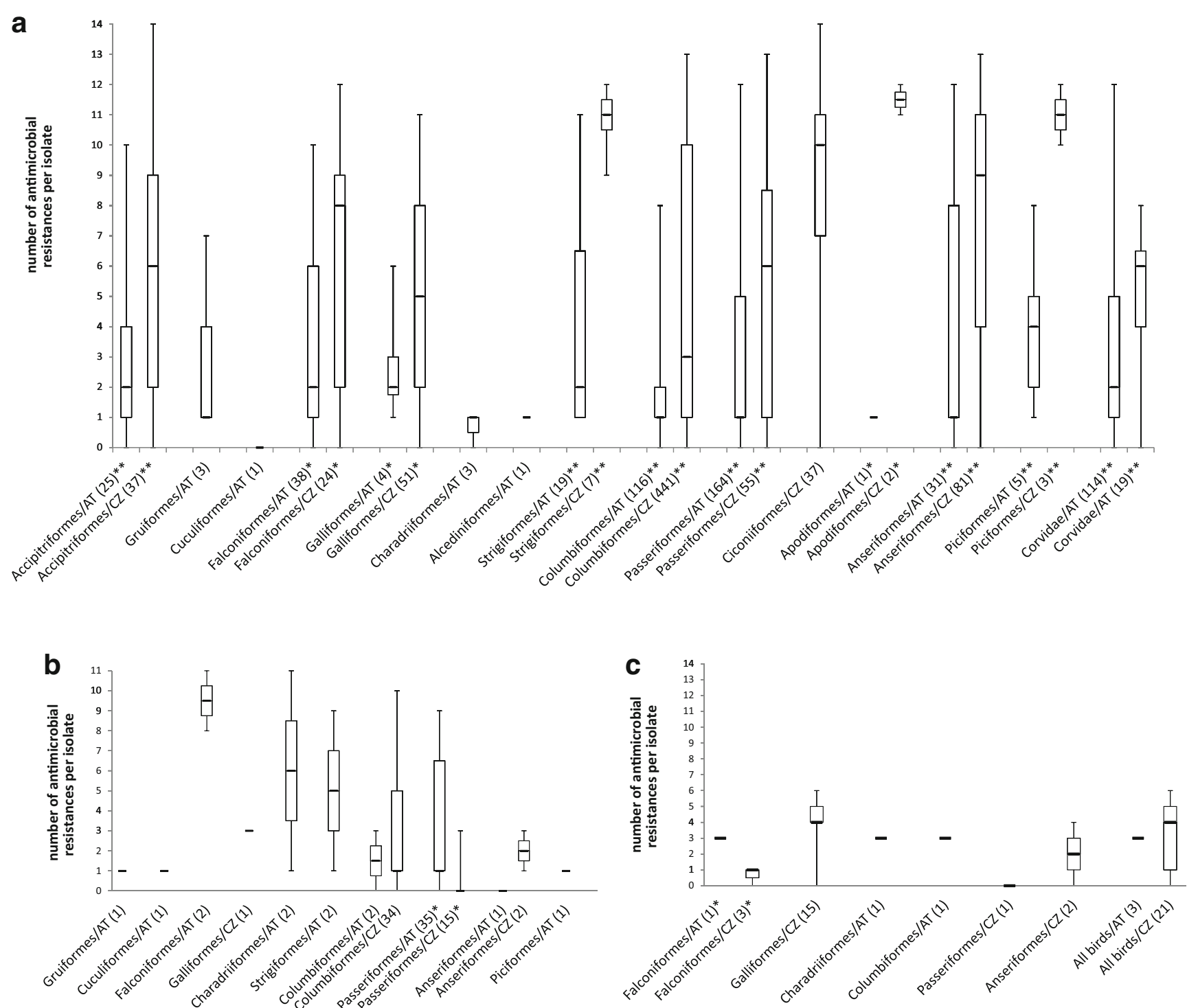

Fig. 3 Distribution of antimicrobial resistances of E. coli (a), Campylobacter spp. (b) and Salmonella spp. (c) isolates according to the orders of birds. For each bacterial isolate, the number of antimicrobial substances the isolate was resistant to was counted. Then, separately for both countries and for each order of bird, the minimum,

to certain antimicrobial substances is remarkable. This strongly indicates that AMR testing of only one isolate per bird might not reflect the actual AMR situation.

In the latest antibiotic monitoring report released by the European Food Safety Authority (EFSA and ECDC 2015), rising resistances against ampicillin, sulfonamides, tetracycline and streptomycin in E. coli isolates from humans were mentioned, whereas resistances to gentamycin, cefotaxime and chloramphenicol were generally low. These findings are different to the ones obtained for the wild birds within the actual study. For example, for gentamycin, the resistances were also low but for chloramphenicol and for third-generation cephalosporines, the resistances were, at least in the Czech Republic, considerably high. median, first and third quartile and maximum were calculated. Significant differences between the mean values of Austrian and Czech isolates are labelled $(* * p \leq 0.01 ; * p \leq 0.05)$ and the numbers of Austrian $(A T)$ and Czech $(C Z)$ isolates are given in parenthesis

Extended spectrum $\beta$-lactamases (ESBLs) are secondary, plasmid coded type-A $\beta$-lactames which mediate resistance to penicillines, cephalosporines and monobactames (Guenther et al. 2011). A large proportion (47.8\%) of the Czech E. coli isolates was classified as "probably ESBL", which corresponds to the number of isolates resistant to ceftriaxone. ESBL rates of up to $32 \%$ in E. coli isolated from wildlife have been found, depending on the species and region (Guenther et al. 2011). However, the evaluation of ESBLs was not the aim of the actual study and therefore the finding of ESBL isolates was not further confirmed by additional analyses which are needed for verified conclusions. 
Bacteria isolated from migrating birds and birds of aquaticassociated species (waterfowl, gulls and waders) are shown to carry more antibiotic resistances than other species (Loncaric et al. 2013). This could partially be confirmed in our study: E. coli isolated from Anseriformes, Apodiformes and Piciformes had the highest mean AMR values, but for the last two orders, the number of tested samples was too low to draw a significant conclusion. Anseriformes may pick up more resistances because of their aquatic lifestyle and contact with liquid wastewater. For the same reasons, Corvidae and gulls are considered to be an important reservoir and vectors for antimicrobial resistances (Dolejska et al. 2007; Literak et al. 2012). This was not supported by our study as the mean antibiotic resistance of $E$. coli isolated from Corvidae was low (2.56), even when compared to the complete order of Passeriformes (2.73). The sample size of gulls (Charadriiformes) was too small to draw a definite conclusion but all of those $E$. coli isolates were either fully susceptible or resistant against only one antimicrobial substance.

Many national surveillance programs for Campylobacter show high levels of resistance to tetracycline and ciprofloxacin (in humans, retail meat and food animals). However, resistance to erythromycin and gentamicin in $C$. jejuni, which is a major cause of zoonotic infections, remains low (Ge et al. 2013). These findings were also noticed for the Campylobacter isolated from wild birds within the present study, although by far most resistances were seen to trimethoprim-sulfamethoxazole. Clinically important is especially a co-resistance against ciprofloxacin and erythromycin because it endangers an effective treatment of human infections (EFSA and ECDC 2015). This critical co-resistance was seen only in $4 \%$ of the Campylobacter isolates from wild birds, although more than a third of the isolates $(34.34 \%)$ were multi-resistant. In general, more resistances are found in C. coli than in C. jejuni (EFSA and ECDC 2015; Dudzic et al. 2016), a tendency also noticed in the actual study. All Campylobacter spp. isolated from Italian birds of prey were susceptible to chloramphenicol, erythromycin, gentamicin and streptomycin but resistant to amoxicillin, ciprofloxacin, tetracycline and nalidixic acid (Dipineto et al. 2014). Similar resistances were found in wild birds in Sweden but at much lower levels (0.7 to 3.6\%), and in the case of metronidazole, the resistance prevalence was higher (14.6\%) (Waldenström et al. 2005). In Finland, only resistance to tetracycline (11.4\%) was observed (Olkkola et al. 2016). Isolates from raptors (mainly long-eared owls) had the highest prevalence of resistance (Waldenström et al. 2005). Also in our study, Campylobacter isolated from Falconiformes showed the highest level of resistances when compared to other orders of birds. However, this observation could not be confirmed for the isolates from Strigiformes. The Campylobacter isolated from Columbiformes had in general a moderate level of AMR, also to ciprofloxacin, and most resistances were seen to trimethoprim-sulfamethoxazole. An investigation about
C. jejuni isolates from homing pigeons kept in lofts found complete susceptibility to erythromycin and tetracycline but $46.0 \%$ of the isolates were resistant to ciprofloxacin (Teske et al. 2013). In contrast, all 40 Campylobacter isolates (mainly C. coli) tested from free-living waterfowl in Spain were completely susceptible to ciprofloxacin, enrofloxacin, nalidixic acid, gentamicin, erythromycin, tetracycline and chloramphenicol using a disc diffusion method (Antilles et al. 2015). The different methods used for AMR testing might be one of the reasons for the heterologous results between the different studies, apart from regional and host species differences. It can be concluded, that, although the general overall resistance in Campylobacter isolates in the actual study is high, especially to trimethoprim-sulfamethoxazole, the resistant to critical antibiotics as erythromycin, gentamicin, telithromycin and chloramphenicol is rather low.

Only a few studies about AMR in Salmonella spp. isolated from wild birds exist: Salmonella spp. isolated from faeces of North American corvids were completely susceptible but $67 \%$ of European samples were resistant to one or more antibiotics. Most resistances were found against nalidixic acid (9 samples), tetracycline (8 samples) and trimethoprim-sulfamethoxazole (4 samples) (Janecko et al. 2015). Three out of 15 Salmonella spp. isolated from Passerine wild bird faeces in Spain had antibiotic resistances and were resistant to aminopenicillins, aminoglycosides, tetracyclines (all 3 birds), sulphonamides ( 2 birds) and phenicols (1 bird) (Andres et al. 2013). These findings reflect the AMR situation in humans in Europe with the highest resistance levels against ampicillin (36.1\%), sulphonamides (35.7\%) and tetracyclines (34.5\%) (EFSA and ECDC 2015), but are not supported in our study where all Salmonella spp. isolates were susceptible to ampicillin and trimethoprim-sulfamethoxazole. However, more than $70 \%$ of the Czech Salmonella isolates were resistant to tetracycline. On the other side, all isolates were susceptible to ciprofloxacin and most of the isolates to second- and third-generation cephalosporines, which are considered to be critical for treatment of Salmonella spp. infections in humans (EFSA and ECDC 2015).

For all three bacterial species investigated in the actual study, it can be concluded that antimicrobial resistances in wild birds are widespread, sometimes to a remarkable degree. Although the investigated Austrian and the Czech regions are relatively similar in terms of environmental conditions for wild birds, the differences in regard to antimicrobial resistances are in certain ways considerable. Bias like sampling strategy (in Austria mainly single birds from many different locations, in Czech Republic mainly groups of birds from a few locations) could be a possible reason. Our study provides valid baseline values for AMR monitoring in wild birds in this densely populated region which should be continued not only because resistant bacteria could be transmitted to humans but also because bacteria in wild birds are a good indicator of AMR distribution in wildlife and environment. 
Acknowledgements Open access funding provided by University of Veterinary Medicine Vienna. The authors thank Dr. Zora Knotkova, CSc., Dr. Radka Kapounova and Dr. Marin Ptacek for their technical skills during the samples collection. This work was performed within the TAV (Training centre for avian medicine) project, funded by the European Regional Development Fund, Cross-border Cooperation Programme Austria-Czech Republic 2007-2013.

Open Access This article is distributed under the terms of the Creative Commons Attribution 4.0 International License (http:// creativecommons.org/licenses/by/4.0/), which permits unrestricted use, distribution, and reproduction in any medium, provided you give appropriate credit to the original author(s) and the source, provide a link to the Creative Commons license, and indicate if changes were made.

\section{References}

Alispahic M, Hummel K, Jandreski-Cvetkovic D, Nöbauer K, RazzaziFazeli E, Hess M, Hess C (2010) Species-specific identification and differentiation of Arcobacter, Helicobacter and Campylobacter by full-spectral matrix-associated laser desorption/ionization time of flight mass spectrometry analysis. J Med Microbiol 59:295-301

Andres S, Vico JP, Garrido V, Grillo MJ, Samper S, Gavin P, HerreraLeon S, Mainar-Jaime RC (2013) Epidemiology of subclinical salmonellosis in wild birds from an area of high prevalence of pig salmonellosis: phenotypic and genetic profiles of Salmonella isolates. Zoonoses Public Health 60:355-365

Antilles N, Sanglas A, Cerda-Cuellar M (2015) Free-living waterfowl as a source of zoonotic bacteria in a dense wild bird population area in northeastern Spain. Transbound Emerg Dis 62:516-521

BirdLife International (2015a) Country profile: Austria http://www. birdlife.org/datazone/country/austria. Accessed 23 June 2015

BirdLife International (2015b) Country profile: Czech Republic http:// www.birdlife.org/datazone/country/czech-republic. Accessed 23 June 2015

Bonnedahl J, Järhult JD (2014) Antibiotic resistance in wild birds. Ups J Med Sci 119:113-116

Clinical and Laboratory Standards Institute (2013) Performance standards for antimicrobial disk and dilution susceptibility tests for bacteria isolated from animals; Second Informational Supplement. VET01-S2

Clinical and Laboratory Standards Institute (2014) Performance for antimicrobial susceptibility testing; Twenty-Fourth Informational Supplement M100-S24

Cole D, Drum DJ, Stalknecht DE, White DG, Lee MD, Ayers S, Sobsey M, Maurer JJ (2005) Free-living Canada geese and antimicrobial resistance. Emerg Infect Dis 11:935-938

Dipineto L, De Luca Bossa LM, Russo TP, Cutino EA, Gargiulo A, Ciccarelli F, Raia P, Menna LF, Fioretti A (2014) Campylobacter spp. and birds of prey. Avian Dis 58:303-305

Dolejska M, Cizek A, Literak I (2007) High prevalence of antimicrobialresistant genes and integrons in Escherichia coli isolates from blackheaded gulls in the Czech Republic. J Appl Microbiol 103:11-19

Dolejska M, Bierosova B, Kohoutova L, Literak I, Cizek A (2009) Antibiotic-resistant Salmonella and Escherichia coli isolates with integrons and extended-spectrum beta-lactamases in surface water and sympatric black-headed gulls. J Appl Microbiol 106:1941-1950

Dudzic A, Urban-Chmiel R, Stepien-Pysniak D, Dec M, Puchalski A, Wernicki A (2016) Isolation, identification and antibiotic resistance of Campylobacter strains isolated from domestic and free-living pigeons. Brit Poult Sci 57:172-178

EFSA (European Food Safety Authority) and ECDC (European Centre for Disease Prevention and Control) (2015) EU Summary Report on antimicrobial resistance in zoonotic and indicator bacteria from humans, animals and food in 2013. EFSA J 13(2):4036
Ge B, Wang F, Sjölund-Karlsson M, McDermott PF (2013) Antimicrobial resistance in Campylobacter: susceptibility testing methods and resistance trends. J Microbiol Methods 95:57-67

Guenther S, Ewers C, Wieler LH (2011) Extended-spectrum beta-lactamases producing $E$. coli in wildlife, yet another form of environmental pollution? Front Microbiol. doi:10.3389/fmicb.2011.00246

Hasan B, Melhus A, Sandegren L, Alam M, Olsen B (2014) The gull (Chroicocephalus brunnicephalus) as an environmental bioindicator and reservoir for antibiotic resistance on the coastlines of the Bay of Bengal. Microb Drug Resist 20:466-471

Janecko N, Cizek A, Halova D, Karpiskova R, Myskova P, Literak I (2015) Prevalence, characterization and antibiotic resistance of Salmonella isolates in large corvid species of Europe and North America between 2010 and 2013. Zoonoses Public Health 62:292-300

Konicek C, Vodrazka P, Bartak P, Knotek Z, Hess C, Racka K, Hess M, Troxler S (2016) Detection of zoonotic pathogens in wild birds in the cross-border region Austria - Czech Republic. J Wildl Dis 52:850-861

Literak I, Micudova M, Tausova D, Cizek A, Dolejska M, Papousek I, Prochazka J, Vojtech J, Borleis F, Guardone L, Guenther S, Hordowski J, Lejas C, Meissner W, Marcos BF, Tucakov M (2012) Plasmid-mediated quinolone resistance genes in fecal bacteria from rooks commonly wintering throughout Europe. Microb Drug Resist 18:567-573

Livermore DM (2003) Bacterial resistance: origins, epidemiology, and impact. Clin Infect Dis 36:S11-S23

Loncaric I, Stalder GL, Mehinagic K, Rosengarten R, Hoelzl F, Knauer F, Walzer C (2013) Comparison of ESBL - and AmpC producing Enterobacteriaceae and methicillin-resistant Staphylococcus aureus (MRSA) isolated from migratory and resident population of rooks (Corvus frugilegus) in Austria. PLoS One 8:e84048

Olkkola S, Nykäsenoja S, Raulo S, Llarena AK, Kovanen S, Kivistö R, Myllyniemi AL, Hänninen ML (2016) Antimicrobial resistance and multilocus sequence types of Finnish Campylobacter jejuni isolates from multiple sources. Zoonoses Public Health 63:10-19

Popoff MY, Le Minor L (2001) Antigenic formulas of the Salmonella serovars, 8th revision, World Health Organization Collaborating Centre for Reference and Research on Salmonella. Pasteur Institute, Paris

Scallan E, Hoekstra RM, Angulo FJ, Tauxe RV, Widdowson MA, Roy SL, Jones JL, Griffin PM (2011) Foodborne illness acquired in the United States - major pathogens. Emerg Infect Dis 17:7-15

Sjolund M, Bonnedahl J, Hernandez J, Bengtsson S, Cederbrant G, Pinhassi J, Kahlmeter G, Olsen B (2008) Dissemination of multidrug-resistant bacteria into the Arctic. Emerg Infect Dis 14:70-72

Smith KE, Anderson F, Medus C, Leano F, Adams J (2005) Outbreaks of salmonellosis at elementary schools associated with dissection of owl pellets. Vector Borne Zoonotic Dis 5:133-136

Stedt J, Bonnedahl J, Hernandez J, McMahon BJ, Hasan B, Olsen B, Drobni M, Waldenstrom J (2014) Antibiotic resistance patterns in Escherichia coli from gulls in nine European countries. Infect Ecol Epidemiol. doi:10.3402/iee.v4.21565

Teske L, Ryll M, Rubbenstroth D, Hanel I, Hartmann M, Kreienbrock L, Rautenschlein S (2013) Epidemiological investigations on the possible risk of distribution of zoonotic bacteria through apparently healthy homing pigeons. Avian Pathol 42:397-407

Tizard I (2004) Salmonellosis in wild birds. Semin Avian Exotic Pet Med 13: $50-66$

Waldenström J, Broman T, Carlsson I, Hasselquist D, Achterberg RP, Wagenaar JA, Olsen B (2002) Prevalence of Campylobacter jejuni, Campylobacter lari, and Campylobacter coli in different ecological guilds and taxa of migrating birds. Appl Environ Microbiol 68:59115917

Waldenström J, Mevius D, Veldman K, Broman T, Hasselquist D, Olsen B (2005) Antimicrobial resistance profiles of Campylobacter jejuni isolates from wild birds in Sweden. Appl Environ Microbiol 71: $2438-2441$ 